\title{
Microwave-Assisted Acid and Base Hydrolysis of Intact Proteins Containing Disulfide Bonds for Protein Sequence Analysis by Mass Spectrometry
}

\author{
Bela Reiz and Liang Li \\ Department of Chemistry, University of Alberta, Edmonton, Alberta, Canada
}

Controlled hydrolysis of proteins to generate peptide ladders combined with mass spectrometric analysis of the resultant peptides can be used for protein sequencing. In this paper, two methods of improving the microwave-assisted protein hydrolysis process are described to enable rapid sequencing of proteins containing disulfide bonds and increase sequence coverage, respectively. It was demonstrated that proteins containing disulfide bonds could be sequenced by MS analysis by first performing hydrolysis for less than $2 \mathrm{~min}$, followed by $1 \mathrm{~h}$ of reduction to release the peptides originally linked by disulfide bonds. It was shown that a strong base could be used as a catalyst for microwave-assisted protein hydrolysis, producing complementary sequence information to that generated by microwave-assisted acid hydrolysis. However, using either acid or base hydrolysis, amide bond breakages in small regions of the polypeptide chains of the model proteins (e.g., cytochrome $c$ and lysozyme) were not detected. Dynamic light scattering measurement of the proteins solubilized in an acid or base indicated that protein-protein interaction or aggregation was not the cause of the failure to hydrolyze certain amide bonds. It was speculated that there were some unknown local structures that might play a role in preventing an acid or base from reacting with the peptide bonds therein. (J Am Soc Mass Spectrom 2010, 21, 1596-1605) (C) 2010 American Society for Mass Spectrometry

$\mathrm{M}$ icrowave-assisted acid hydrolysis (MAAH) has been shown to be a useful tool for degrading proteins into peptides for mass spectrometric analysis [1-11]. Using a strong acid, such as $6 \mathrm{M}$ $\mathrm{HCl}$, peptides from $\mathrm{N}$-terminal and C-terminal sequences of a protein can be generated by MAAH and the analysis of the peptide ladders by mass spectrometry (MS) can be used to sequence a protein [1]. For low mass proteins $(<20,000 \mathrm{Da})$, complete sequence information from the overlapping N-terminal and C-terminal peptide ladders can be produced, which is useful for analyzing terminal peptide sequences and characterizing protein modifications. For larger proteins, N-terminal and Cterminal peptide sequence information can still be obtained, providing an alternative method to the traditional Edman sequencing technique [12]. In addition, using a weak acid, such as $25 \%$ trifluoroacetic acid (TFA), terminal and internal peptides can be generated by MAAH for shotgun proteome analysis [2]. This method is particularly useful for analyzing insoluble proteins, such as those found in tissue samples [4, 9], as the microwave technique can assist in protein solubili-

Address reprint requests to Professor L. Li, Department of Chemistry, University of Alberta, Edmonton, Alberta T6G 2G2, Canada. E-mail: Liang.Li@ualberta.ca zation during MAAH, and proteins not efficiently digested by using conventional enzymes [11]. In addition, microwave hydrolysis can accelerate the hydrolysis process and generate more reproducible results, compared with heating alone, and it can be more readily applied to membrane proteins as heating alone causes precipitation of membrane proteins in acids which prevent them from further degradation [1, 2].

In this work, we report two related enabling methods to improve hydrolysis mass spectrometry for protein sequencing. It has been shown that sequencing proteins containing disulfide bonds by MAAH is a more challenging task than sequencing straight chain proteins [1]. Reduction of disulfide bonds is required before MAAH and incomplete reduction results in poor sequence coverage. Overnight reduction of disulfide bonds is often needed. However, even using a prolonged reduction process, some proteins with disulfide bonds not readily accessible to the reducing agents (e.g., prions) $[13,14]$ cannot be readily sequenced. There are also reports of difficulty in sequencing highly folded proteins by the technique $[7,8,15]$. Here we describe an effective method in dealing with proteins containing disulfide bonds. It involves first performing protein hydrolysis for less than $2 \mathrm{~min}$, followed by $1 \mathrm{~h}$ of disulfide bond reduction to release for MS analysis the 
peptides originally linked by disulfide bonds. However, with MAAH, not all amide bonds are hydrolyzed; occasionally, missing peptide ladders corresponding to the breakage of certain amide bonds in the protein sequence are observed. To increase the sequence coverage, we report a method, which was shown to produce complementary sequence information to MAAH, of using a strong base for microwave-assisted protein hydrolysis. Finally, dynamic light scattering (DLS) measurements have been used to provide some insight on the relation of peptide bond hydrolysis and protein structures.

\section{Experimental}

\section{Chemicals and Reagents}

Unless otherwise noted, all chemicals were purchased from Sigma (St. Louis, MO, USA) and were of analytical grade. For HPLC separations, MS analysis, and preparation of digestions, Optima grade water and acetonitrile (ACN) were used (Fisher Scientific, Mississauga, $\mathrm{ON}$, Canada); 37\% $\mathrm{HCl}$ (ACS grade) was from Merck KGaA, Darmstadt, Germany; $\mathrm{NaOH}$ was from Fisher Scientific (Mississauga, ON, Canada); horse heart cytochrome $c$, chicken egg white lysozyme, and horse heart myoglobin were obtained from Sigma Aldrich (Oakville, ON, Canada).

\section{Dynamic Light Scattering}

DLS spectra were recorded with a Malvern Zetasizer Nano-S (Malvern Instruments Ltd., Worcestershire, UK). Scans were performed in a $1 \mathrm{~mL}$ cuvette. Protein samples at $1 \mathrm{mg} \mathrm{mL}^{-1}$ concentration were prepared in $50 \mathrm{mM} \mathrm{NaAc}$ buffer, $\mathrm{pH}$ 5.5. For DLS experiments under acidic or basic conditions a $2 \mathrm{mg} \mathrm{mL}^{-1}$ protein sample prepared in $50 \mathrm{mM} \mathrm{NaAc}$ was mixed 1:1 (vol/ vol) with $6 \mathrm{M} \mathrm{HCl}$ or $2 \mathrm{M} \mathrm{NaOH}$. The DLS spectra for all samples were recorded immediately after mixing.

\section{Microwave-Assisted Acid and Base Hydrolysis}

For MAAH, $1 \mathrm{mg} \mathrm{mL}^{-1}$ protein samples were prepared in $50 \mathrm{mM} \mathrm{NaAc}, \mathrm{pH}$ 5.5. An aliquot of $40 \mu \mathrm{L}$ of this stock solution was mixed with an equal volume of $6 \mathrm{M}$ $\mathrm{HCl}$ in a $1.5 \mathrm{~mL}$ polypropylene vial. For the microwaveassisted base hydrolysis (MABH) experiments, $1 \mathrm{mg}$ $\mathrm{mL}^{-1}$ protein samples were prepared in $50 \mathrm{mM} \mathrm{NaAc}$, $\mathrm{pH}$ 5.5. An aliquot of $40 \mu \mathrm{L}$ of this stock solution was mixed with $2 \mu \mathrm{L}$ of $450 \mathrm{mM}$ DTT and $40 \mu \mathrm{L}$ of $\mathrm{NaOH}$ in a $1.5 \mathrm{~mL}$ polypropylene vial. The vial was capped and placed inside a household microwave oven with 1000 $\mathrm{W}$ power output at $2450 \mathrm{MHz}$, with excess microwave energy being absorbed by $100 \mathrm{~mL}$ of water in a loosely covered container beside the sample. Samples were subjected to microwave irradiation for 30 and $60 \mathrm{~s}$ for MAAH and $30 \mathrm{~s}$ to $3 \mathrm{~min}$ for $\mathrm{MABH}$. The temperature of the sample during microwave was unknown as we did not have a means of measuring it in the simple microwave oven. However, the temperature could not be very high as the sample still remained as a liquid after hydrolysis.

MAAH samples were cooled and dried in a SpeedVac vacuum centrifuge to remove all the acid. For MALDI-MS experiments, horse heart cytochrome $c$ samples were reconstituted in $80 \mu \mathrm{L}$ of $50 \% \mathrm{ACN} / \mathrm{H}_{2} \mathrm{O}$. The $\mathrm{ACN}$ was removed by vacuum centrifugation. Lysozyme samples were reconstituted in $30 \mu \mathrm{L}$ of $6 \mathrm{M}$ guanidine $\mathrm{HCl} .2 \mu \mathrm{L}$ of $450 \mathrm{mM}$ dithiothreitol (DTT) was added and the samples were diluted to a final concentration of $3 \mathrm{M}$ guanidine $\mathrm{HCl}$ in $200 \mathrm{mM} \mathrm{NH} \mathrm{HCO}_{3}, \mathrm{pH}$ 8.0. Reduction of the disulfide bond was performed by incubation for $60 \mathrm{~min}$ at $37^{\circ} \mathrm{C}$.

$\mathrm{MABH}$ samples were neutralized using concentrated $\mathrm{HCl}$, to a final $\mathrm{pH}$ of 8.0. DTT was added to a final concentration of $15 \mathrm{mM}$ and the mixture was incubated at $37^{\circ} \mathrm{C}$ for $60 \mathrm{~min}$ to reduce the disulfide bonds.

Before desalting, all samples were acidified and diluted with TFA to a final $\mathrm{pH}$ of 2.0. For LC-MS and FT-ICR-MS experiments, MAAH samples were reconstituted in $50 \% \mathrm{ACN} / \mathrm{H}_{2} \mathrm{O}$, followed by the removal of the ACN using vacuum centrifugation. Samples were acidified and desalted without disulfide bond reduction.

\section{Desalting}

Desalting was carried out in an Agilent 1100 HPLC system (Palo Alto, CA, USA) [16]. In brief, desalting of the hydrolysates was performed on a $4.6 \mathrm{~mm} \times 5 \mathrm{~cm}$ Polaris C18 A column with a particle size of $3 \mu \mathrm{m}$ and $300 \AA$ pore (Varian, MA, USA). After loading of the polypeptide sample, the column was flushed with $97.5 \%$ mobile phase A $(0.1 \%$ TFA in water $)$ and $2.5 \%$ mobile phase $\mathrm{B}(0.1 \%$ TFA in $\mathrm{ACN})$ at a flow rate of 1 $\mathrm{mL} / \mathrm{min}$ and the salts were effectively removed. Subsequently, the concentration of phase B in the mobile phase was step-wise increased to $90 \%$ to ensure complete elution of the polypeptides from the column.

\section{MALDI-TOF MS of Sequence Ladders}

The desalted samples were concentrated in a SpeedVac vacuum centrifuge. The samples were then mixed with the matrix solution of $\alpha$-cyano-4-hydrocynnamic acid (CHCA) and spotted on a MALDI plate for matrixassisted laser desorption ionization (MALDI) analysis. The MALDI-TOF mass spectra were obtained on an Applied Biosystems/MDS SCIEX 4800 Plus MALDITOF/TOF Analyzer (AB Sciex, Foster City, CA, USA). Ionization was performed with a diode-pumped $\mathrm{Nd}$ : YAG laser at $355 \mathrm{~nm}$. The analyzer was used in a linear mode of operation. The peptide ion peak picking and mass assignment were done automatically using the peak picking software in the 4800 Plus system. 


\section{LC-MS}

The LC-MS experiments were carried out on an Agilent 6220 Accurate-Mass TOF LC/MS system (Palo Alto, CA, USA). In brief, samples were injected on a $75 \times 0.5$ $\mathrm{mm}$ Poroshell C8 column with a particle size of $5 \mu \mathrm{m}$ (Agilent) with an Opti-pak trap cartridge. After loading of the sample, the column was flushed for $3 \mathrm{~min}$ at a $0.15 \mathrm{~mL} \mathrm{~min}^{-1}$ flow rate with $95 \%$ mobile phase A $(0.1 \%$ formic acid (FA) in water) and $5 \%$ mobile phase $B(0.1 \%$ FA in ACN) to effectively remove the salts. Subsequently, the concentration of phase B in the mobile phase was gradually increased to $95 \%$ over a period of $7 \mathrm{~min}$ to ensure elution of the polypeptide fractions from the column. The column was thermostatted at $70{ }^{\circ} \mathrm{C}$.

\section{FT-ICR-MS}

FT-MS spectra were recorded using a Bruker 9.4T Apex-Qe FTICR from Bruker Daltonics (Billerica, MA, USA) by diluting the samples with $0.2 \%$ acetic acid in $50 \% \mathrm{MeOH} / \mathrm{H}_{2} \mathrm{O}$ and injecting them by direct infusion with a syringe pump at a flow rate of $3 \mu \mathrm{L} \mathrm{min}{ }^{-1}$ and the use of electrospray as a source of ionization.

\section{Results and Discussion}

Hen egg white lysozyme is a $14.3 \mathrm{kDa}$ protein containing 129 amino acid residues. The protein contains five helices formed by 44 residues and nine strands formed by 15 residues [17]. The structure of the protein is stabilized by four different disulfide bonds linking all eight cysteine residues of the protein. The primary and secondary structures [17] of the protein with the four disulfide bonds are shown in Figure 1a. Sequencing of lysozyme using MAAH followed by MALDI-TOF-MS, which involved the reduction of the disulfide bonds before MAAH, has been previously reported [1]. The best signal-to-noise ratio and sequence coverage were obtained by reduction of the disulfide bonds for $15 \mathrm{~h}$ using DTT as reducing agent, followed by MAAH. To speed up this process and to determine how important disulfide bond reduction is for the success of MAAH, we examined the effectiveness of the method without prior reduction of the disulfide bonds.

Figure $1 \mathrm{~b}$ shows the MALDI-TOF mass spectrum of lysozyme after MAAH in $3 \mathrm{M} \mathrm{HCl}$ with 1 min irradiation time. The MAAH was performed without prior reduction of the disulfide bonds and also no reducing reagent was present in the mixture during the MAAH process. A similar spectrum was obtained when DTT was present in the protein solution during MAAH. Figure $1 \mathrm{~b}$ shows that the peaks observed are those corresponding to different charged states of the molecular ion peak and the triply charged dimer. Under these conditions, no peaks corresponding to hydrolysis peptide products were observed in the mass spectrum. One of the four disulfide bonds in lysozyme connects Cys6 to Cys127 (see Figure 1a). Even if hydrolysis of a peptide bond located between these two Cys residues

(a)
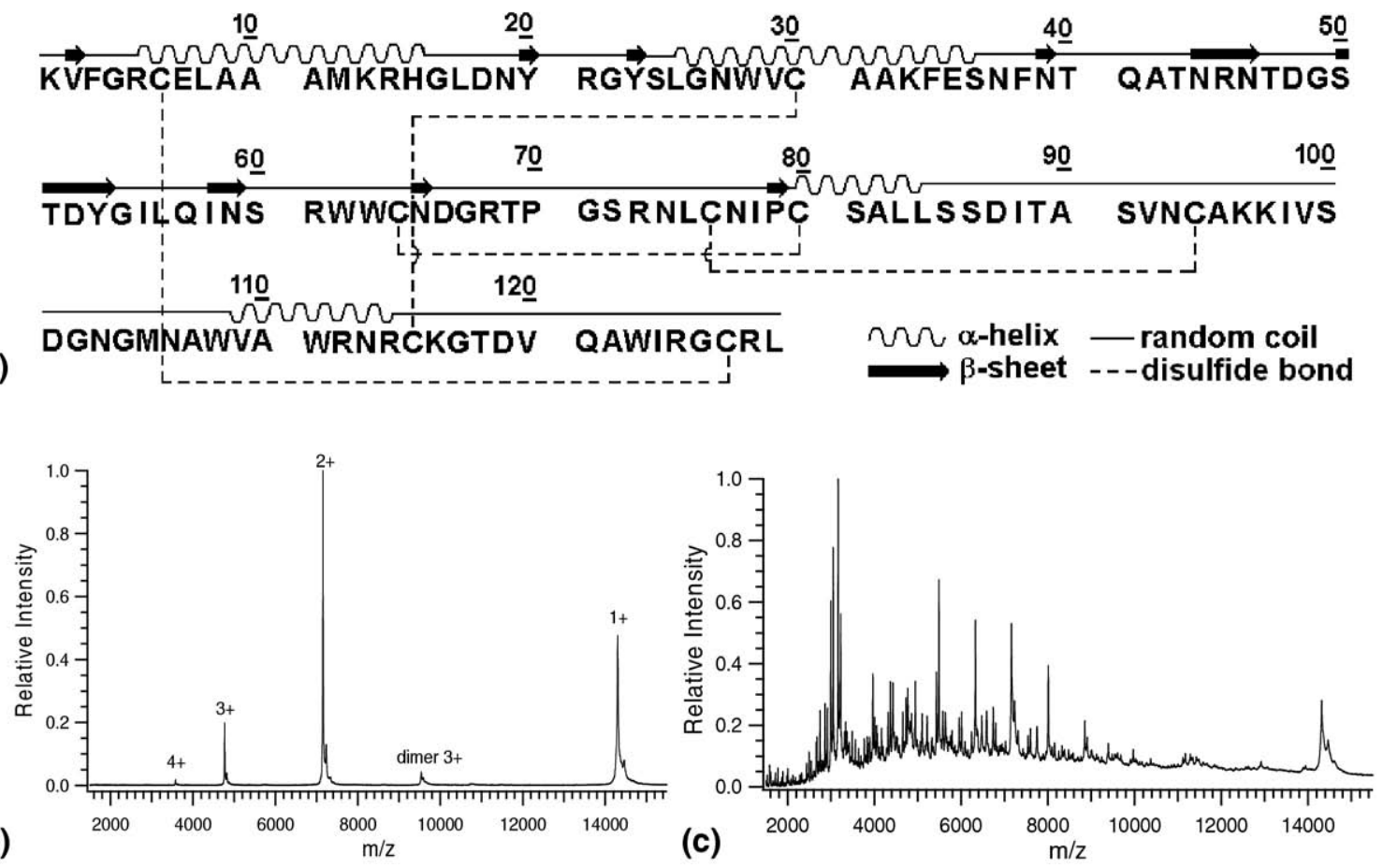

Figure 1. MALDI-TOF mass spectra of (a) primary and secondary structure of lysozyme along with the four disulfide bonds, (b) lysozyme after MAAH in $3 \mathrm{M} \mathrm{HCl}$ for 1 min irradiation, and (c) lysozyme after hydrolysis in $3 \mathrm{M} \mathrm{HCl}$ and 1 min of irradiation time followed by reduction with DTT. 
occurs during the MAAH process, the two peptide fragments corresponding to the $\mathrm{N}$ - and C-terminal fragments will be linked by this disulfide bond and as a result the peaks of the hydrolyzed protein will show up as a single peak, with a molecular mass that would be 18 Da higher than the intact molecular ion. The other three disulfide bonds also link different parts of the protein, further decreasing the possibility of detecting hydrolysate peaks when hydrolysis of peptide bonds does occur between linked Cys residues. If the hydrolysis of the peptide bond occurs between Arg5 and Cys6, the highest molecular mass fragment would be KVFGR with a mass of $606.37 \mathrm{Da}$. If the hydrolysis of the peptide bond occurs between Cys127 and Leu128, the fragment produced will be LR having a mass of 288.20 Da. These two peptides were not detected using MALDI-TOF-MS because of the presence of matrix peaks in the low mass region and ion suppression from the protein peaks.

The absence of other peaks in the spectrum shows that when a controlled hydrolysis is performed, peptide bond hydrolysis occurs only once per protein molecule, which should result in a +18 Da mass shift from the protein molecular mass. Two bond breakages would result in the observation of internal fragment peaks in the spectrum. Because our MALDI-TOF-MS instrument did not provide enough resolution and mass accuracy to differentiate a hydrolyzed peak with a +18 Da shift from an oxidized protein ion peak with a +16 Da shift or sodium adduct ion of the protein with a $+22 \mathrm{Da}$ shift, we used electrospray ionization (ESI) TOF-MS to analyze the hydrolysate. We also used cytochrome $c$, a protein with no disulfide bonds, as a control (data not shown). Figure 2 shows the molecular ion regions of the deconvoluted ESI-TOF mass spectra of lysozyme before and after MAAH for 30 and $60 \mathrm{~s}$. The mass spectrum of lysozyme without acid treatment (i.e., the original sample) is also shown in Figure 2 for comparison. Figure $2 a$ and $b$ show similar spectra, indicating that brief acid treatment of lysozyme does not alter the structure or affect the mass spectrometric results. As Figure $2 b$ shows, before hydrolysis, the protein molecular ion peak was detected along with a likely oxidation peak $(\mathrm{m} / \mathrm{z} \sim$ 14,322), a potassium adduct ion peak $(\mathrm{m} / \mathrm{z} \sim 14,342)$, and other unassigned oxidation and/or adduct peaks. After hydrolysis, some intact proteins still remained in the hydrolysate solutions. In the case of cytochrome $c$, no +18-Da peak in the molecular ion region was detected after hydrolysis (data not shown). This is not surprising, as this protein does not have any disulfide bonds and, therefore, hydrolysis of any of the peptide bonds would result in an $\mathrm{N}$ - and a C-terminal polypeptide, and no +18 Da mass shift of the molecular ion should be observed. However, for lysozyme, the +18 Da hydrolysate molecular ion peak was clearly observed, as shown in Figure 2d. Note that +1 Da shift in lysozyme (i.e., from $m / z 14,305$ to 14,306 ) can be seen between the sample before irradiation and after $60 \mathrm{~s}$ of irradiation. This shift can most probably be attributed to

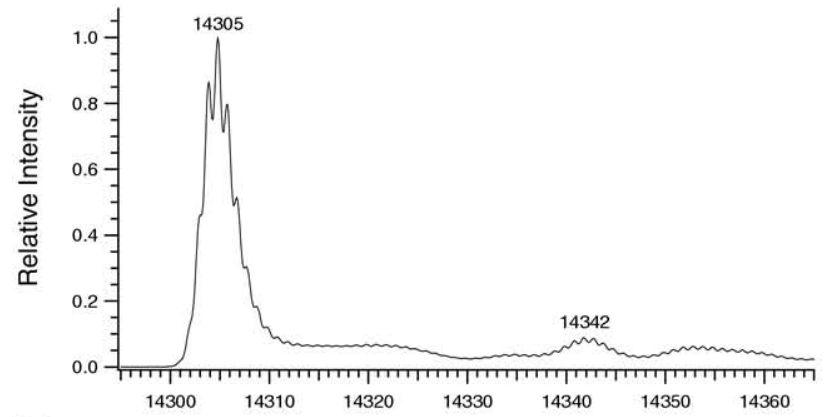

(a)

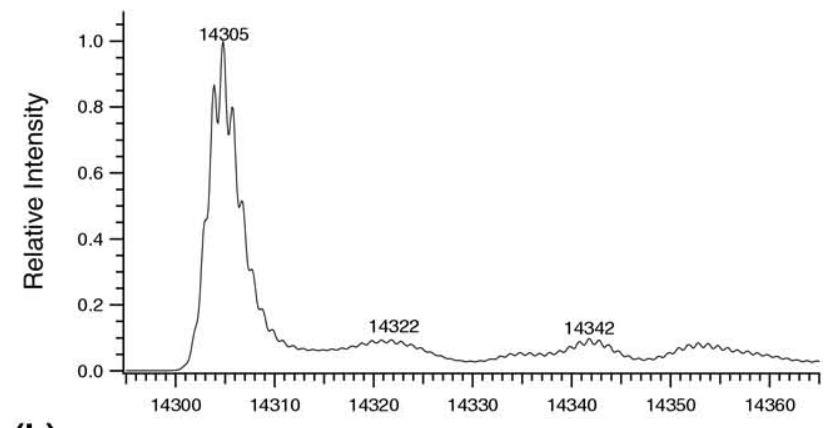

(b)

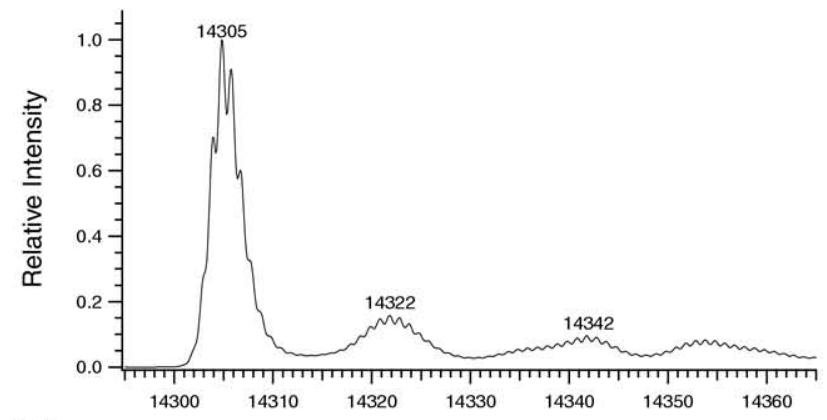

(c)

$\mathrm{m} / \mathrm{z}$

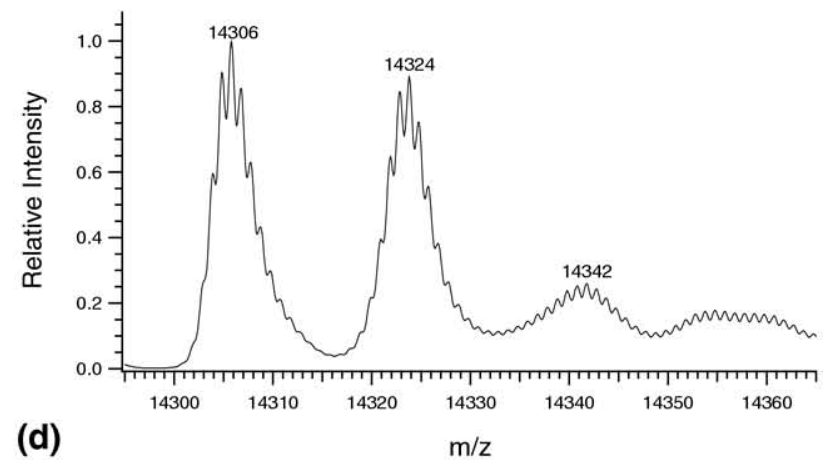

Figure 2. Molecular ion regions of deconvoluted ESI mass spectra of lysozyme obtained under various sample conditions: (a) lysozyme was solubilized in $0.1 \%$ formic acid, (b) lysozyme was solubilized in $3 \mathrm{M}$ $\mathrm{HCl}$, immediately followed by drying in a Speedvac and the dried sample was solubilized in $0.1 \%$ formic acid, (c) lysozyme was solubilized in $3 \mathrm{M} \mathrm{HCl}$, followed by microwave irradiation for $30 \mathrm{~s}$, and the solution was dried by Speedvac and then solubilized in $0.1 \%$ formic acid, (d) same as (c) except microwave irradiation was $1 \mathrm{~min}$.

deamidation $(\mathrm{N} \rightarrow \mathrm{D}$ or $\mathrm{Q} \rightarrow \mathrm{E})$. For lysozyme, no peaks were detected at +36 Da or higher in the mass spectra, changes which would correspond to two or more 
hydrolyzed peptide bonds. These mass shift results were further confirmed by ESI FT-ICR-MS (data not shown).

Figure 1c shows the MALDI-TOF mass spectrum of the lysozyme hydrolysate after adjustment of the solution $\mathrm{pH}$ and reduction of the disulfide bonds with DTT for $1 \mathrm{~h}$. This spectrum shows hydrolysate peaks corresponding to the $\mathrm{N}$ - and C-terminal peptide ladders, which can be seen in the expanded spectra (Figure 3). Supplemental Table S1, which can be found in the electronic version of this article, lists the peak mass assignments, theoretical masses of peptides, mass errors, $\mathrm{S} / \mathrm{N}$ ratios, and resolution. From the mass spec- trometric data, a peptide bond hydrolysis map for lysozyme can be readily obtained (see Figure 4a). As Figure 4 a shows, the entire sequence of lysozyme has been covered by the $\mathrm{N}$ - and C-terminal peptide ladders with many overlapping bond breakage sites.

The above example demonstrates that peptide ladders of proteins containing disulfide bonds can be generated by performing $\mathrm{MAAH}$ in $3 \mathrm{M} \mathrm{HCl}$, followed by adjusting the solution $\mathrm{pH}$ and then DTT reduction. There are reports of carrying out reduction and acid hydrolysis in one step under a special circumstance where a relatively mild acid, formic [18] or acetic acid [19], was used to hydrolyze amide bonds involving

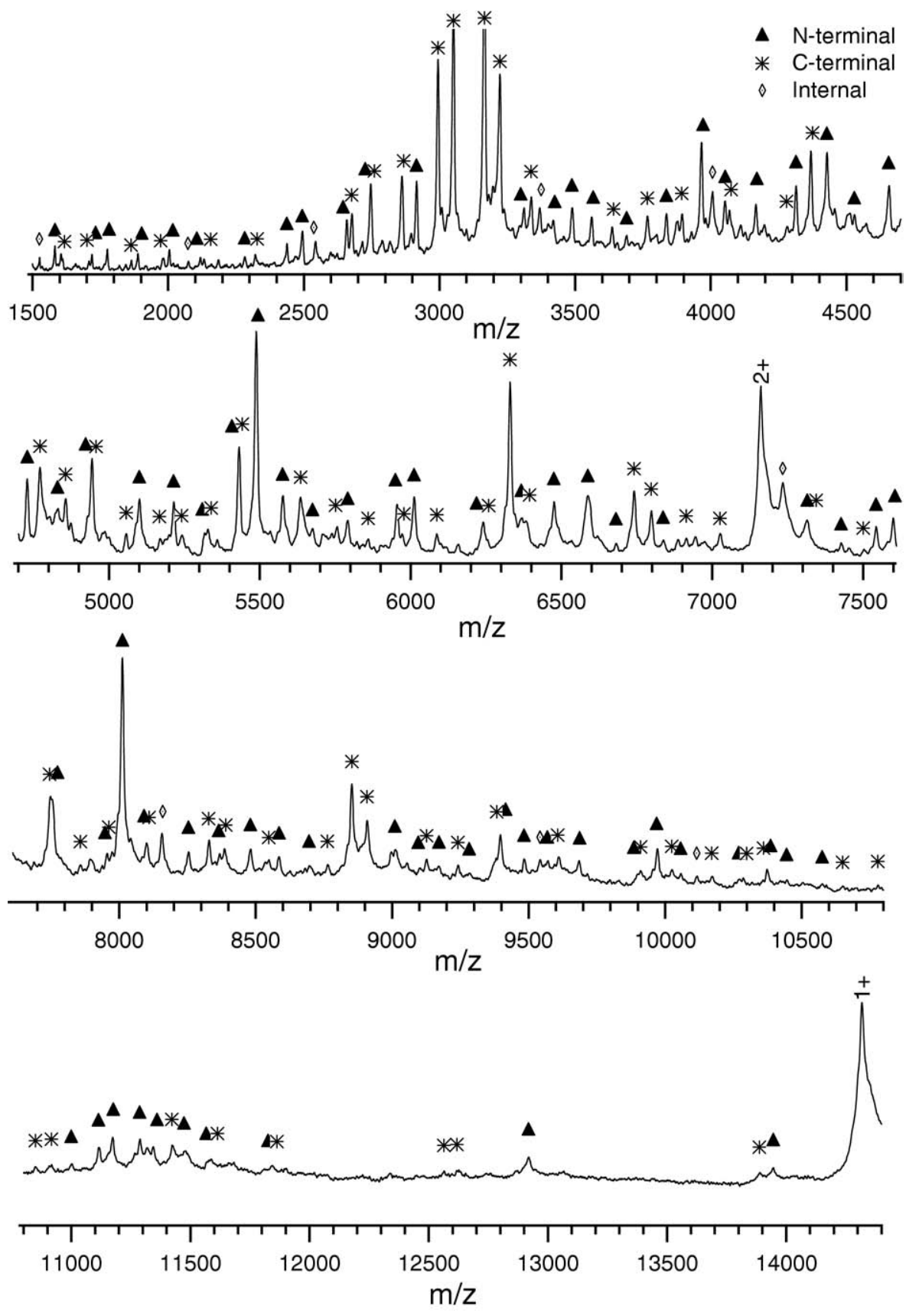

Figure 3. Expanded mass spectrum of Figure 1c. 


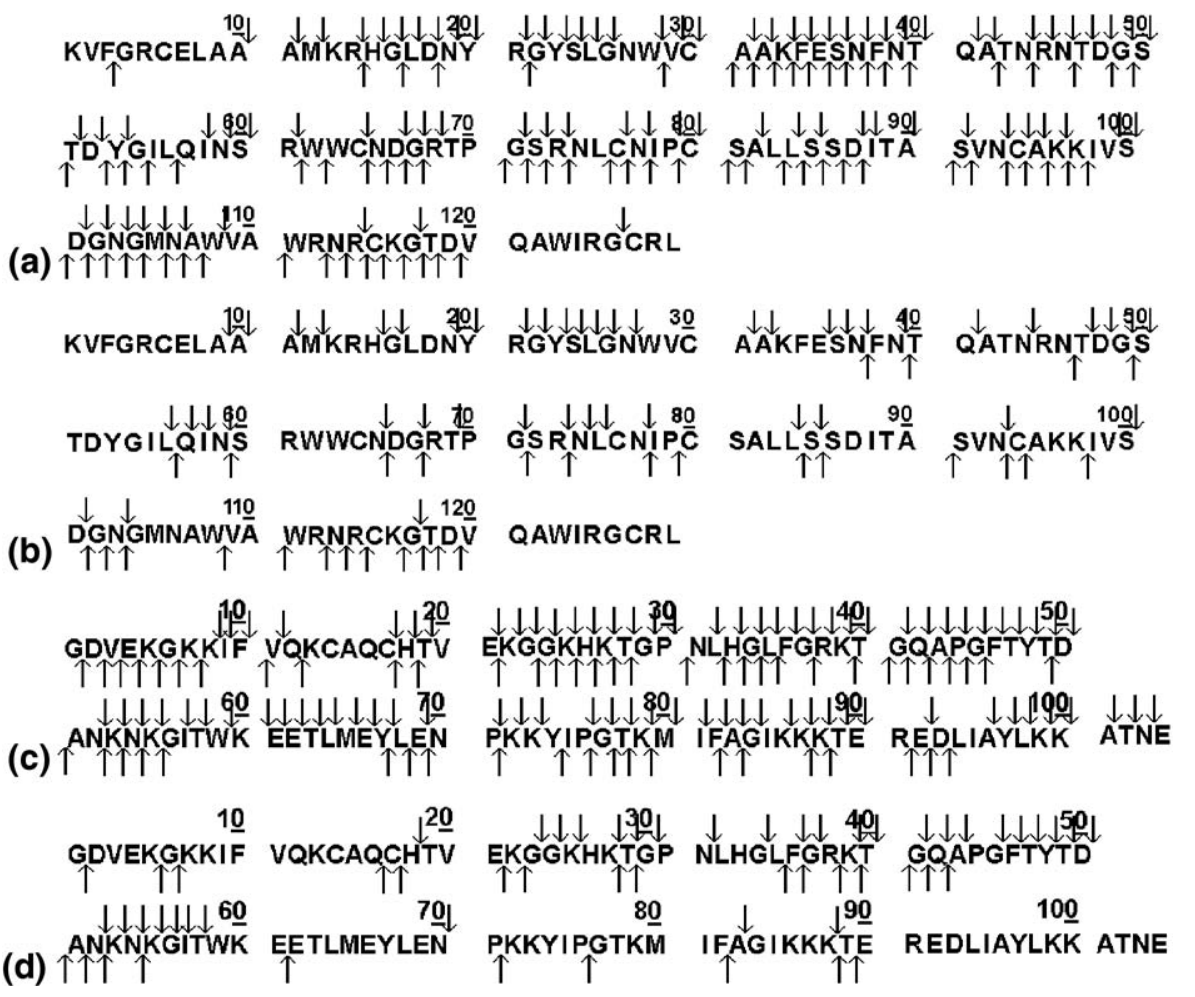

Figure 4. Peptide bond hydrolysis maps of (a) lysozyme in $3 \mathrm{M} \mathrm{HCl}$ and 1 min irradiation time followed by DTT reduction of the disulfide bonds, (b) lysozyme in $1 \mathrm{M} \mathrm{NaOH}$ and $30 \mathrm{~s}$ irradiation time, (c) cytochrome $c$ in $3 \mathrm{M} \mathrm{HCl}$ and 1 min irradiation time, and (d) cytochrome $c$ in $1 \mathrm{M} \mathrm{NaOH}$ and $30 \mathrm{~s}$ irradiation time. (down arrow) Hydrolysis site identified by the detection of the N-terminal peptide; (up arrow) hydrolysis site identified by the detection of the C-terminal peptide.

aspartic acid (D-cleavage) to generate a few peptides. One report indicated that using insulin as a test protein, the low $\mathrm{pH}$ used for the microwave D-cleavage $(\mathrm{pH}$ 1-2) was found to lower the efficiency of the microwave disulfide bond cleavage, most likely due to thiol group protonation [18]. In our work, we could not generate any peptide ladders when DTT was added to the protein solution containing $3 \mathrm{M} \mathrm{HCl}$ for MAAH. Clearly, DTT in $3 \mathrm{M} \mathrm{HCl}$ does not work for the reduction of disulfide bonds. Another reducing reagent, tris(2-carboxyethyl) phosphine (TCEP), was also tested in $3 \mathrm{M} \mathrm{HCl} \mathrm{MAAH}$, but failed to produce useful peptide ladders for protein sequencing.

Interestingly, Figure 4a shows that there are some gaps where bond breakage products were not detected from the $\mathrm{N}$ - or C-terminal peptide ladders. For example, the peptides corresponding to peptide bond breakage between residue $27(\mathrm{~N})$ and residue $28(\mathrm{~W})$ were not detected.

To investigate the possibility of generating different hydrolysis maps that may provide complementary sequence information to MAAH, we used a strong base, $\mathrm{NaOH}$, as a hydrolysis reagent. We examined both the effect of concentration and irradiation time on the hydrolysis process. In our experiments, a stock solution of $1 \mathrm{mg} \mathrm{mL}-1$ of lysozyme was prepared and then mixed with varying concentrations of $\mathrm{NaOH}$. The mixtures were individually hydrolyzed using different mi- crowave irradiation times. The tested concentrations of $\mathrm{NaOH}$ after mixing 1 to 1 ( $\mathrm{vol} / \mathrm{vol})$ with the protein sample were $0.5,1,2$, and $3 \mathrm{M}$. Irradiation was performed for $30 \mathrm{~s}, 1,2$, or $3 \mathrm{~min}$. It was found that microwave irradiation of the sample in $3 \mathrm{M} \mathrm{NaOH}$ was degrading the Eppendorf vials. Therefore only concentrations of $0.5,1$, and $2 \mathrm{M} \mathrm{NaOH}$ were further tested. For $30 \mathrm{~s}$ irradiation, mass spectra with good signal-tonoise $(\mathrm{S} / \mathrm{N})$ ratios were obtained for all $\mathrm{NaOH}$ concentrations (see Figure 5). These spectra show peaks corresponding to both $\mathrm{N}$ - and C-terminal ladders. The $\mathrm{S} / \mathrm{N}$ ratios in 0.5 and $1 \mathrm{M} \mathrm{NaOH}$ are very similar, although a better sequence coverage was obtained in $1 \mathrm{M} \mathrm{NaOH}$. Increasing the concentration to $2 \mathrm{M}$ did not improve the sequence coverage and resulted in peaks with similar or lower $\mathrm{S} / \mathrm{N}$ ratios compared with $1 \mathrm{M} \mathrm{NaOH}$.

For microwave-assisted base hydrolysis (MABH) of lysozyme, optimization of the microwave irradiation time was also important. It was found that as irradiation time increased to $1 \mathrm{~min}$, the best $\mathrm{S} / \mathrm{N}$ ratio was obtained when $0.5 \mathrm{M} \mathrm{NaOH}$ was used (see Supplemental Figure S1A). For 1 and $2 \mathrm{M} \mathrm{NaOH}$, peaks with good $\mathrm{S} / \mathrm{N}$ ratios were detected in the low mass region $(<6,000 \mathrm{Da})$, but very low intensity peaks or no peaks were observed for the higher mass region (Figure S1B and $\mathrm{C}$ ). Even though good $\mathrm{S} / \mathrm{N}$ ratios were obtained for 1 min irradiation in $0.5 \mathrm{M} \mathrm{NaOH}$, the sequence coverage was lower than for $30 \mathrm{~s}$ irradiation in $1 \mathrm{M} \mathrm{NaOH}$. A 

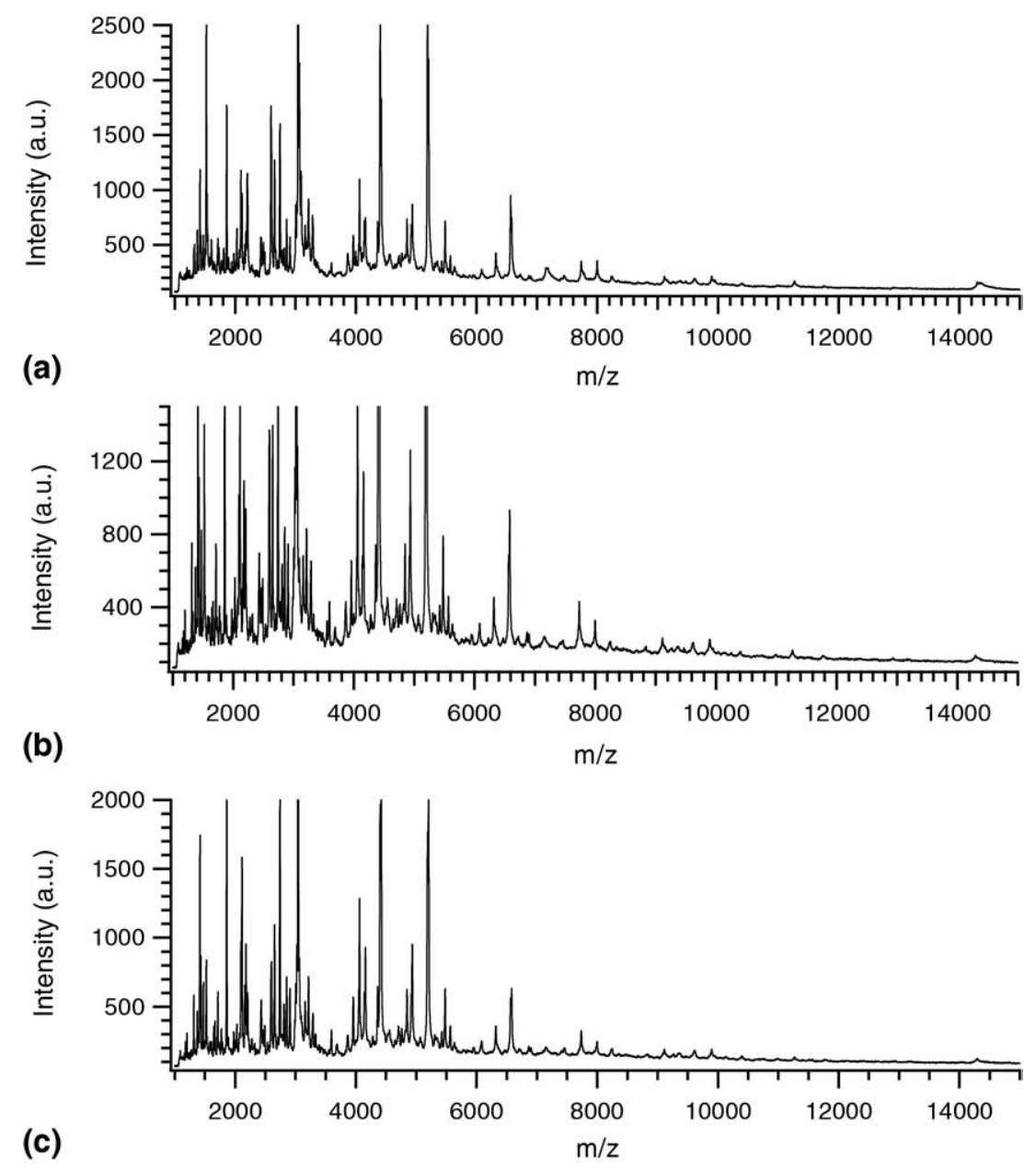

Figure 5. MALDI-TOF mass spectra of the MABH hydrolysates of lysozyme after $30 \mathrm{~s}$ irradiation time in (a) $0.5 \mathrm{M} \mathrm{NaOH}$, (b) $1 \mathrm{M} \mathrm{NaOH}$, and (c) $2 \mathrm{M} \mathrm{NaOH}$.

further increase of the irradiation time to 2 min or even $3 \mathrm{~min}$ resulted in very low intensity or disappearance of high mass terminal peptide peaks and the appearance of internal peptide peaks (see Supplemental Figures S2 and S3). As all the intact protein was consumed after 2 or $3 \mathrm{~min}$ irradiation, the internal peptide peaks became the dominant feature of the spectra. A long exposure to the microwave radiation would eventually result in a mixture of amino acids.

From the above results, it was concluded that the optimal condition for MABH of lysozyme was using $30 \mathrm{~s}$ microwave irradiation in $1 \mathrm{M} \mathrm{NaOH}$, i.e., the MALDI-TOF mass spectrum shown in Figure 5b represents the best spectrum. The expanded spectra are shown in Figure 6 with the corresponding hydrolysis map shown in Figure $4 \mathrm{~b}$. It should be noted that this optimal condition appears to be applicable to other standard proteins. For example, Supplemental Figure S4 shows the expanded mass spectra of the hydrolysate from $\mathrm{MABH}$ of cytochrome $c$. Figure $4 \mathrm{~d}$ shows the MABH hydrolysis map of cytochrome $c$. For comparison, the MAAH hydrolysis map of cytochrome $c$ is shown in Figure 4c and the expanded mass spectra of the MAAH hydrolysate are shown in Supplemental Figure S5. Another example is shown in Supplemental Figure S6 where the expanded mass spectra of the hydrolysate from $\mathrm{MABH}$ of horse heart myoglobin along with the hydrolysis map are displayed. It should be noted that the hydrolysis maps are very reproducible; the MALDI-TOF mass spectral patterns and relative intensities of peaks from the protein hydrolysate in replicate runs are almost identical.

There are several important observations related to $\mathrm{MABH}$ of proteins. As in MAAH, base hydrolysis can be controlled by using optimal base concentration and microwave irradiation time to generate $\mathrm{N}$ - and Cterminal peptides with no or little internal peptides. Hydrolysis takes place in one peptide bond per protein molecule for most protein molecules. Some internal peptides may be observed, but their proportion is very small compared with the terminal peptides (see, for example, the spectrum shown in Figure 3). The presence of disulfide bonds in a protein, as in the case of lysozyme, does not hinder the hydrolysis process. The method of carrying out hydrolysis followed by DTT reduction for $1 \mathrm{~h}$ can also be applied to $\mathrm{MABH}$ for rapid 

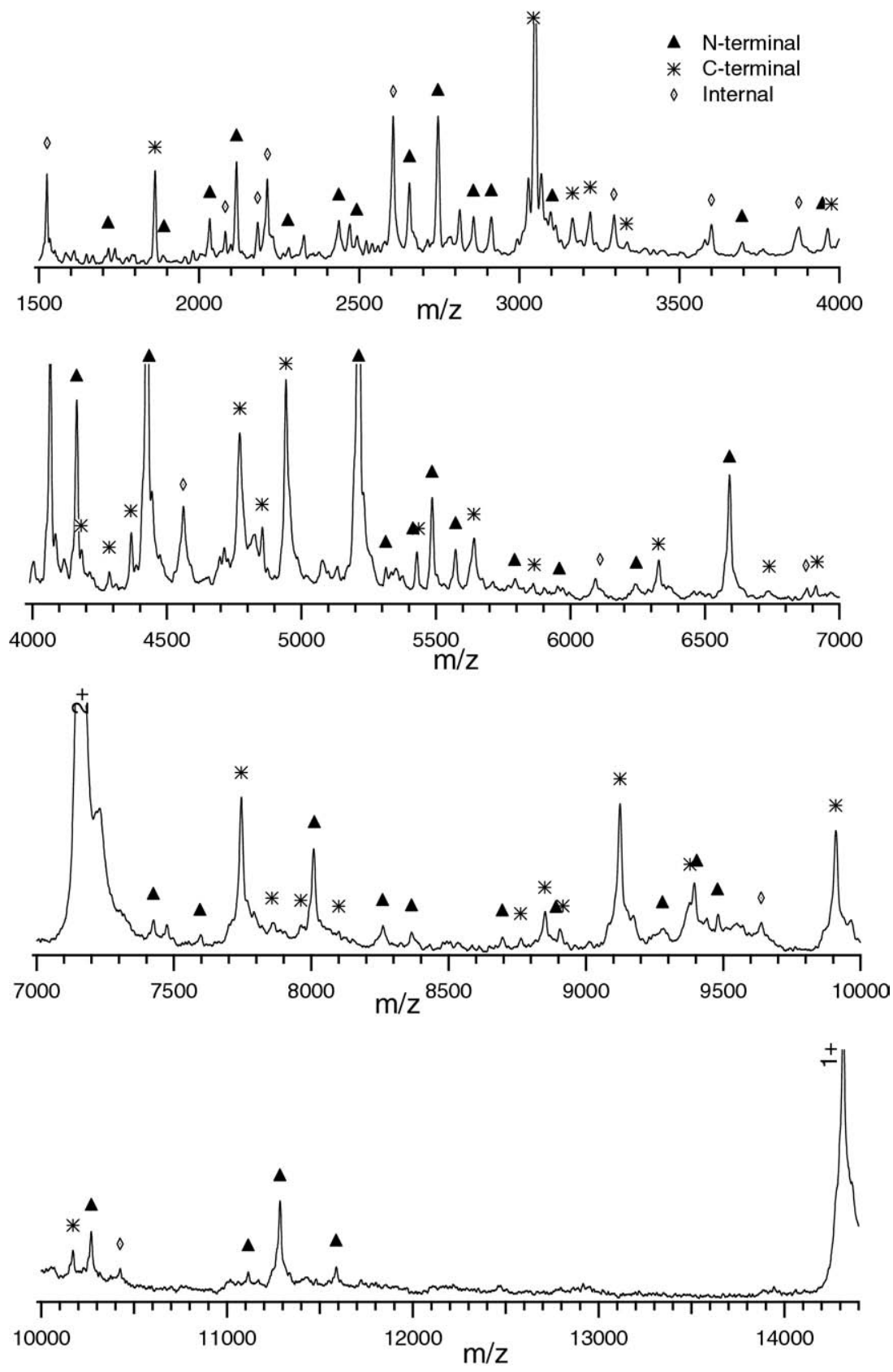

Figure 6. Expanded mass spectrum of Figure $5 \mathbf{b}$.

sequencing of proteins. Although peptide ladders generated by $\mathrm{MABH}$ cannot be used to deduce the full sequence of a protein, they can cover the entire sequence of a small protein $(<20,000 \mathrm{Da})$, as can be seen in Figure $4 \mathrm{~b}$ and $\mathrm{d}$ for lysozyme and cytochrome $c$, respectively. However, MABH MALDI-TOF MS detects less than half of the peptide ladders observed in MAAH. Thus, it is less capable of examining individual amino acids of a protein to pinpoint specific amino acid substitution/modification or of de novo sequencing of a protein. Nevertheless, it is still a valuable tool for providing complementary ladder sequencing information to the MAAH method. For example, in the hydro- lysis maps of lysozyme shown in Figure 4a (from $\mathrm{MAAH}$ ) and Figure $4 \mathrm{~b}$ (from $\mathrm{MABH}$ ), the N-terminal ladder misses the steps between N27 and W28, L56 and Q57, Q57 and I58, N65 and D66, T69 and P70, N74 and L75, and L75 and C76 in the MAAH map, but they are present in the $\mathrm{MABH}$ map. The C-terminal ladder misse the steps between W108 and V109, N59 and S60 in the MAAH map and these steps are detectable in the $\mathrm{MABH}$ map. Even for cytochrome $c$ where MAAH has already generated a very comprehensive map (Figure $4 \mathrm{c}$ ), three missing steps in the N-terminal ladder, between N32 and L33, G57 and I58, and N71 and P72, are covered by the MABH map (Figure $4 \mathrm{~d}$ ). For the C- 
terminal ladder, seven missing steps in MAAH between T90 and E91, E62 and E63, A52 and N53, R39 and K40, F37 and G38, K23 and G24, and Q17 and C18 are covered by the MABH map.

The difference observed in the MAAH and $\mathrm{MABH}$ MALDI-TOF MS results reflects most likely the difference in the hydrolysis process of the two methods, rather than the MS detection. If the same peptide ladders had been generated by MAAH and MABH, similar mass spectra would be expected. Ion suppression difference in MALDI analysis of the peptide mixtures cannot readily explain the vast difference in mass spectral patterns observed from MAAH and $\mathrm{MABH}$ hydrolysates. For example, no dominant peptide peaks were found in the MAAH or MABH mass spectra and, in both cases, peptide peaks span over a wide mass range with decreasing signals for higher mass ion detection. Apparently, MABH is more selective in hydrolyzing peptide bonds compared with MAAH. Certain bonds in a protein were more preferentially hydrolyzed in $\mathrm{MABH}$, resulting in fewer terminal peptides being formed. The acid [20] and base [21, 22] hydrolysis reaction mechanisms are shown in Supplemental Figure S7. Based on the reaction mechanisms alone, one cannot predict which type of peptide bonds is more readily hydrolyzed. Future work on analyzing a large number of proteins may provide some statistical insight on the specificity of bond breakage involved in $\mathrm{MABH}$.

As shown in Figure 4, even acid hydrolysis does not produce a complete sequence ladder. There appear to be regions in the polypeptide chain not readily accessible to acid or base hydrolysis. One possibility for the existence of these regions may be related to protein aggregation where strong protein-protein interactions in local domains may prevent the acid or base from reacting with the peptide bonds therein. We have examined this issue by using dynamic light scattering (DLS) to monitor changes in the aggregation state under the different solvent conditions. A summary of the DLS results is shown in Table 1 . In the case of cytochrome $c$ dissolved in sodium acetate buffer at $\mathrm{pH} 5.5$, a monodisperse peak was observed in DLS and a hydrody-

Table 1. Hydrodynamic radii determined by dynamic light scattering for cytochrome $c$ and lysozyme under different solvent conditions

\begin{tabular}{|c|c|c|c|c|}
\hline \multirow[b]{2}{*}{ Protein } & \multirow[b]{2}{*}{ Solvent } & \multirow{2}{*}{$\begin{array}{c}\mathrm{R}_{\mathrm{H}} \\
(\mathrm{nm})\end{array}$} & \multicolumn{2}{|c|}{ Molecular Mass (kDa) } \\
\hline & & & Estimated $^{a}$ & Expected \\
\hline \multirow{3}{*}{$\begin{array}{c}\text { Cytochrome } \\
c \text { (horse) }\end{array}$} & $50 \mathrm{mM} \mathrm{NaAc}$ & 1.7 & 12.1 & 12.3 \\
\hline & $3 \mathrm{M} \mathrm{HCl}$ & $2.7^{\mathrm{b}}$ & 34.3 & - \\
\hline & $1 \mathrm{M} \mathrm{NaOH}$ & 2.0 & 17.9 & - \\
\hline \multirow{3}{*}{$\begin{array}{l}\text { Lysozyme } \\
\text { (hen egg } \\
\text { white) }\end{array}$} & $50 \mathrm{mM} \mathrm{NaAc}$ & 1.8 & 13.3 & 14.3 \\
\hline & $3 \mathrm{M} \mathrm{HCl}$ & 1.7 & 10.9 & - \\
\hline & $1 \mathrm{M} \mathrm{NaOH}$ & 2.1 & 18.0 & - \\
\hline
\end{tabular}

aEstimation is based on the assumption that the protein remains as spherical molecule.

bUnlike the other monodisperse peaks, this is a broad peak with $29 \%$ polydispersity at the full width of the peak. namic radius of $1.7 \mathrm{~nm}$ was determined, which gives a predicted molecular mass of $12.1 \mathrm{kDa}$. This is very close to the expected molecular mass of $12.3 \mathrm{kDa}$ and shows that the protein existed as a pure monomer. For cytochrome $c$ in $3 \mathrm{M} \mathrm{HCl}$, a mean hydrodynamic radius of $2.7 \mathrm{~nm}$ was found with a relatively high polydispersity of $29 \%$. If we assume that the protein maintains a spherical structure this gives a predicted molecular mass of $34.3 \mathrm{kDa}$, which would indicate oligomerization of the protein. However, an unfolded protein can also increase the hydrodynamic radius. Thus, a solution of cytochrome $c$ in $3 \mathrm{M} \mathrm{HCl}$ might contain either a mixture of properly folded molecules and partially or fully unfolded conformers or a mixture of oligomers and partially or fully folded/unfolded molecules. DLS analysis of cytochrome $c$ in $1 \mathrm{M} \mathrm{NaOH}$ showed a monodisperse peak with a hydrodynamic radius of 2.0 $\mathrm{nm}$, which indicates that the protein is monomeric. The slightly higher hydrodynamic radius compared with that found in $\mathrm{pH} 5.5$ could indicate a partial unfolding of the protein under highly basic conditions.

For lysozyme, no significant differences have been observed between the different solvent conditions. The DLS plot of lysozyme in $50 \mathrm{mM}$ sodium acetate at $\mathrm{pH}$ 5.5 showed a hydrodynamic radius of $1.8 \mathrm{~nm}$, which is very close to the theoretical value of $1.9 \mathrm{~nm}$ and indicates that the peak is corresponding to a pure lysozyme monomer. Under the acidic conditions (3 M $\mathrm{HCl}$ ) the peak showed a hydrodynamic radius of 1.7 $\mathrm{nm}$. The DLS plot for lysozyme under basic conditions (1 $\mathrm{M} \mathrm{NaOH}$ ) showed a monodisperse peak with a hydrodynamic radius of $2.1 \mathrm{~nm}$, which is a clear indication that the lysozyme stays monomeric. However, compared with the protein in $50 \mathrm{mM} \mathrm{NaAc}$, it must be partially unfolded as the measured radius $(2.1 \mathrm{~nm})$ is slightly higher than $1.8 \mathrm{~nm}$ found in NaAc.

From the above DLS results, clearly protein oligomerization or aggregation did not take place for cytochrome $c$ in $1 \mathrm{M} \mathrm{NaOH}$ or for lysozyme in $1 \mathrm{M}$ $\mathrm{NaOH}$ or $3 \mathrm{M} \mathrm{HCl}$. For cytochrome $c$ in $3 \mathrm{M} \mathrm{HCl}$, no conclusive evidence on oligomerization was present in the DLS data. Note that MAAH of cytochrome $c$ produced the most complete peptide sequence ladders. Thus, it can be concluded that protein aggregation is not the cause of regional preference in peptide bond hydrolysis in both MAAH and $\mathrm{MABH}$. At this stage, we can only speculate that there are regions in the protein sequence that form some unknown structures which prevent either acid or base from accessing these regions for hydrolysis. Alternatively, there is a possibility of correlation between local sequence and resistance of amide bond cleavage; analyzing a large number of proteins in the future may provide statistically meaningful insight on such a correlation.

\section{Conclusions}

We have developed a method of rapid sequencing of proteins containing disulfide bonds. Instead of reduc- 
ing the disulfide bonds overnight using a reducing reagent, we apply $1 \mathrm{~min}$ of microwave-assisted hydrolysis to the protein, followed by $1 \mathrm{~h}$ of reduction of the disulfide bonds in the hydrolysate to release the peptides for MS analysis. We have also developed a method of using a strong base as a catalyst for microwaveassisted protein hydrolysis. Various experimental conditions have been explored to optimize the performance of this $\mathrm{MABH}$ method. We have shown that this method provides complementary sequence coverage to the MAAH method. One interesting observation was that in both MAAH and $\mathrm{MABH}$, hydrolysis of a few amide bonds in the protein sequence was never observed. Dynamic light scattering was carried out to investigate the possible cause of this observation. Proteinprotein interaction or aggregation was not observed for cytochrome $c$ or lysozyme in an acid or base and thus could not be the cause. We speculate the presence of local secondary structures in certain regions of the proteins that prevent acid or base interaction with the amide bonds, resulting in the failure to hydrolyze these amide bonds. Finally, we note that both MAAH and $\mathrm{MABH}$ methods described in this work have been successfully applied to generate ladder sequence information from several recombinant prion constructs, which provide some insight on the hydrolysis resistance cores of the prion proteins [14]. Detailed analysis of prion structures using our methods will be reported in the future.

\section{Acknowledgments}

The authors acknowledge funding for this work by the Natural Sciences and Engineering Research Council of Canada, the Canada Research Chairs program, the PrioNet Canada, and the Alberta Prion Research Institute.

\section{Appendix A \\ Supplementary Material}

Supplementary material associated with this article may be found in the online version at doi:10.1016/ j.jasms.2010.04.012.

\section{References}

1. Zhong, H. Y.; Zhang, Y.; Wen, Z. H.; Li, L. Protein Sequencing by Mass Analysis of Polypeptide Ladders After Controlled Protein Hydrolysis. Nat. Biotechnol. 2004, 22(10), 1291-1296.
2. Zhong, H. Y.; Marcus, S. L.; Li, L. Microwave-Assisted Acid Hydrolysis of Proteins Combined with Liquid Chromatography MALDI MS/MS for Protein Identification. J. Am. Soc. Mass Spectrom. 2005, 16(4), 471-481.

3. Yassine, M. M.; Guo, N.; Zhong, H.; Li, L.; Lucy, C. A. Off-Line Coupling of Preparative Capillary Zone Electrophoresis with Microwave-Assisted Acid Hydrolysis and Matrix-Assisted Laser Desorption Ionization Mass Spectrometry for Protein Sequencing. Anal. Chim. Acta 2007, 597(1), 41-49.

4. Wang, N.; MacKenzie, L.; De Souza, A. G.; Zhong, H. Y.; Goss, G.; Li, L. Proteome Profile of Cytosolic Component of Zebrafish Liver Generated by LC-ESI MS/MS Combined with Trypsin Digestion and MicrowaveAssisted Acid Hydrolysis. J. Proteome Res. 2007, 6(1), 263-272.

5. Swatkoski, S.; Russell, S. C.; Edwards, N.; Fenselau, C. Rapid Chemical Digestion of Small Acid-Soluble Spore Proteins for Analysis of Bacillus spores. Anal. Chem. 2006, 78(1), 181-188.

6. Swatkoski, S.; Gutierrez, P.; Wynne, C.; Petrov, A.; Dinman, J. D.; Edwards, N.; Fenselau, C. Evaluation of Microwave-Accelerated ResidueSpecific Acid Cleavage for Proteomic Applications. J. Proteome Res. 2008, $7(2), 579-586$

7. Sandoval, W. N.; Pharn, V. C.; Lill, J. R. Recent Developments in Microwave-Assisted Protein Chemistries-Can This be Integrated into the Drug Discovery and Validation Process? Drug Discov. Today 2008, 13(23/24), 1075-1081

8. Lill, J. R.; Ingle, E. S.; Liu, P. S.; Pham, V.; Sandoval, W. N. MicrowaveAssisted Proteomics. Mass Spectrom. Rev. 2007, 26(5), 657-671.

9. Gebremedhin, M.; Zhong, H. Y.; Wang, S. H.; Weinfeld, M.; Li, L. Benefit of Microwave-Assisted Acid Hydrolysis of Proteins for Mass Spectrometric Profiling of the Human Heart Tissue Proteome. Rapid Commun. Mass Spectrom. 2007, 21(16), 2779-2783.

10. Sze, S. K.; Wang, W.; Meng, W.; Yuan, R. D.; Guo, T. N.; Zhu, Y.; Tam, J. P. Elucidating the Structure of Cyclotides by Partial Acid Hydrolysis and LC-MS/MS Analysis. Anal. Chem. 2009, 81(3), 1079-1088.

11. Nair, S. S.; Romanuka, J.; Billeter, M.; Skjeldal, L.; Emmett, M. R Nilsson, C. L.; Marshall, A. G. Structural Characterization of an Unusually Stable Cyclic Peptide, Kalata B2 from Oldenlandia affinis. Biochim. Biophys., Acta Proteins Proteom. 2006, 1764(10), 1568-1576.

12. Niall, H. D. Automated Edman Degradation: The Protein Sequenator Methods Enzymol. 1973, 27, 942-1010.

13. Herrmann, L. M.; Caughey, B. The Importance of the Disulfide Bond in Prion Protein Conversion. Neuroreport 1998, 9(11), 2457-2461.

14. Reiz, B.; Bujold, A.; Wishart, D. S.; Li, L. Microwave-Assisted Acid and Base Hydrolysis Combined with MALDI MS for Structural Studies of the Prion Protein. Proceedings of the 56th ASMS Conference on Mass Spectrometry and Allied Topics; Denver, CO, June, 2008.

15. Sandoval, W. N.; Pham, V.; Ingle, E. S.; Liu, P. S.; Lill, J. R. Applications of Microwave-Assisted Proteomics in Biotechnology. Combinat. Chem. High Throughput Screen. 2007, 10(9), 751-765.

16. Wang, N.; Xie, C.; Young, J. B.; Li, L. Off-Line Two-Dimensional Liquid Chromatography with Maximized Sample Loading to Reversed-Phase Liquid Chromatography-Electrospray Ionization Tandem Mass Spectrometry for Shotgun Proteome Analysis. Anal. Chem. 2009, 81(3) 1049-1060.

17. Wang, J.; Dauter, M.; Alkire, R.; Joachimiak, A.; Dauter, Z. Triclinic Lysozyme at 0.65 A Resolution. Acta Crystallogr D, Biol. Crystallogr. 2007, 63(Pt 12), 1254-68.

18. Hauser, N. J.; Basile, F. Online Microwave D-Cleavage LC-ESI-MS/MS of Intact Proteins: Site-Specific Cleavages at Aspartic Acid Residues and Disulfide Bonds. J. Proteome Res. 2008, 7(3), 1012-1026.

19. Li, J. X.; Shefcheck, K.; Callahan, J.; Fenselau, C. Extension of Microwave-Accelerated Residue-Specific Acid Cleavage to Proteins with Carbohydrate Side Chains and Disulfide Linkages. Int. J. Mass Spectrom. 2008, 278(2/3), 109-113.

20. Roberts, J. D.; Caserio, M. C. Basic Principles of Organic Chemistry; W. A. Benjamin, Inc., New York, 1964.

21. Zahn, D. Car-Parrinello Molecular Dynamics Simulation of Base-Catalyzed Amide Hydrolysis in Aqueous Solution. Chem. Phys. Lett. 2004, 383(1/2), 134-137.

22. Zahn, D. On the Role of Water in Amide Hydrolysis. Eur. J. Org. Chem. 2004, 19, 4020-4023. 